\title{
Optimalisasi GERMAS dalam Pencegahan Stunting di Desa Rejosari Kecamatan Polokarto Kabupaten Sukoharjo
}

\author{
${ }^{1 *}$ Fitria Hayu Palupi, ${ }^{1}$ Siskana Dewi Rosita, ${ }^{1}$ Gipfel Remedina \\ ${ }^{1}$ Prodi D3 Kebidanan, STIKes Mitra Husada Karanganyar \\ *Fitria Hayu Palupi, email: fitriahp45@gmail.com
}

(Received: 18 November 2020/Accepted: 16 Januari 2021/Published: 28 Januari 2021)

\begin{abstract}
Abstrak
Hasil Rikesdas 2018 di Indonesia mencapai 30,8\% balita stunting, hal tersebut dapat dikatakan bahwa 3 atau 4 balita terdapat satu anak Indonesia mengalami stunting. Dengan melakukan kegiatan Gerakan Masyarakat Hidup Sehat (GERMAS), maka masyarakat dapat menerapkan pola hidup sehat sebagai bagian dari perilaku masyarakat sehingga masyarakat lebih peduli terhadap kesehatan dengan penerapan perilaku hidup sehat dan penerapan Sanitasi Total Berbasis Masyarakat (STBM) 5 Pilar maka gerakan masyarakat ini juga sangat mendukung upaya penurunan stunting. Gerakan masyarakat sebagai bagian dari strategi yang dapat digunakan agar masyarakat ikut peduli dalam penanganan stunting. Melalui program gerakan masyarakat (GERMAS), terdapat 7 langkah GERMAS yang menjadi panduan dalam menjalani pola hidup yang lebih sehat. Kader Posyandu adalah garda depan pelayanan dan sebagai penggerak masyarakat, maka dengan diakadan penyegaran kader tentang optimasilasi GERMAS dalam pencegahan stunting, kader dapat turut serta dalam promosi, preventif pencegahan stunting. Pengabdian masyarakat ini ini menggunakan metode yang berfokus edukasi pada kader kesehatan yang dikemas dalam mini seminar dalam peningkatan pengetahuan kader tentang stunting dan kegiatan GERMAS, penerapan STBM 5 Pilar dalam kehidupan sehari-hari, sehingga kader dapat melakukan deteksi dini kejadian stunting dan masyarakat tergugah untuk melakukan hidup sehat sesuai dengan anjuran pemerintah dalam gerakan masyarakat
\end{abstract}

Kata Kunci : GERMAS, stunting, kader, STBM

\begin{abstract}
The results of the 2018 Rikesdas in Indonesia reached $30.8 \%$ of children under five are stunted, it can be said that 3 or 4 children under five have one Indonesian child who is stunted. By carrying out the Healthy Living Community Movement (GERMAS), the community can apply a healthy lifestyle as part of community behavior so that people care more about health by implementing healthy living habits and implementing 5 Pillars of Community Lead Total Sanitation (CLTS), this community movement is also strongly supports efforts to reduce stunting. Community movement as part of a strategy that can be used so that people care about stunting handling. Through the community movement program (GERMAS), there are 7 GERMAS steps that serve as a guide in living a healthier lifestyle. Posyandu cadres are at the forefront of services and as community activists, so with the cadres refresher on the optimization of GERMAS in preventing stunting, cadres can participate in promotion and preventive prevention of stunting. This community service uses a method that focuses on education on health cadres which is packaged in a mini seminar inside increasing cadres' knowledge about stunting and GERMAS activities, implementing the 5 Pillar CLTS in daily life, so that cadres can detect early stunting incidents and the community is inspired to live a healthy life in accordance with government recommendations in the community movement
\end{abstract}

Keywords : GERMAS, stunting, cadres, CLTS 


\section{Pendahuluan}

Hasil Rikesdas 2018 menyatakan bahwa 30,8\% balita di Indonesia mengalami stunting. Dengan kata lain, dari 3 atau 4 balita terdapat satu anak Indonesia mengalami stunting. Melihat kondisi yang ada, maka tentunya perlu upaya untuk melakukan gerakan bersama masyarakat untuk mencegah stunting. Berdasarkan wawancara dengan bidan Desa Polokarto, terdapat 2 balita yang mengalami stunting dalam pemeriksaan rutin yang dilaksanakan tahun 2018. Kondisi stunting di Indonesia melebihi batasan WHO pada kejadian stunting kurang dari 20 persen (Kementerian Kesehatan Republik Indonesia, 2018).

Kejadian stunting dewasa ini menjadi perhatian pemerintah, karena seperti fenomena gunung es yaitu tampak sedikit, namun setelah dilakukan pemeriksaan secara spesifik masih terdapat anak yang menderita stunting. Banyak orang tua yang kurang mengetahui bahwa jika anak mengalami gangguan pertumbuhan, itu merupakan tanda dari adanya masalah gizi kronis pada pertumbuhan anak, terlebih pada anak usia di bawah 2 tahun, maka harus segera ditangani dengan tepat (Kementerian Kesehatan Republik Indonesia, 2018).

Apabila anak sudah mengalami stunting maka pada anak tersebut mengalami kondisi kurang gizi yang telah berlangsung dalam waktu yang lama, sehingga mengakibatkan gangguan pertumbuhan. Selain masalah gizi, faktor penyebab terjadinya stunting dapat terjadi karena masalah kebersihan dan sanitasi, polusi, asap rokok serta penggunaan pestisida juga mempengaruhi tumbuh kembang anak (Palupi \& Anggraini, 2017).

Tujuan pembangunan kesehatan adalah meningkatkan kesadaran, kemauan dan kemampuan hidup sehat bagi setiap orang agar terwujud derajat kesehatan yang optimal. Untuk mendukung tujuan tersebut, maka diperlukan partisipasi dari semua pihak, terutama adalah masyarakat itu sendiri. Dengan salah satu pendekatan yang sedang dijalankan oleh sektor kesehatan yaitu Gerakan Masyarakat Hidup Sehat (GERMAS) (Kementerian Kesehatan Republik Indonesia, 2018).

GERMAS merupakan salah satu program pemerintah melalui Kementrian Kesehatan yang memiliki tujuan untuk menciptakan budaya hidup sehat dengan meninggalkan kebiasaan masyarakat dan perilaku yang kurang sehat. Dengan melakukan perilaku hidup sehat, maka gerakan masyarakat ini juga mendukung upaya terjadinya stunting. Gerakan masyarakat ini merupakan salah satu strategi yang dapat digunakan agar masyarakat ikut peduli dalam penanganan stunting. Melalui program gerakan masyarakat (GERMAS), terdapat 7 langkah GERMAS yang menjadi panduan dalam menjalani pola hidup yang lebih sehat antara lain: melakukan aktifitas fisik, makan buah dan sayur, cek kesehatan berkala, diberika ASI eksklusif, Enyahkan rokok, fokus penanganan stunting. Selain itu, penerapan Sanitasi Total Berbasis Masyarakat (STBM) yang terdiri 5 pilar yaitu Stop Buang Air Besar Sembarangan (Stop BABS), Cuci Tangan Pakai Sabun (CTPS), Pengelolaan Air Minum Rumah Tangga (PAM-RT), Pengelolaan Sampah Rumah Tangga serta Pengelolaan Air Limbah Rumah Tangga menjadi sarana pendukung dalam menyehatkan keluarga sehingga dapat mencegah kejadian stunting.

Peran penting dari kader Posyandu sebagai garda terdepan dalam pelayanan kepada masyarakat, selain memberikan informasi kesehatan kepada masyarakat juga sebagai penggerak masyarakat untuk melaksanakan perilaku hidup bersih dan sehat, utama adalah kesehatan ibu dan anak.

Memandang beberapa masalah tersebut maka perlu diadakannya penyegaran kader dengan tema "Optimalisasi GERMAS dalam Pencegahan Stunting di Desa Rejosari Kecamatan Polokarto Kabupaten Sukoharjo".

\section{Metode}

Metode kegiatan pengabdian masyarakat ini adalah dengan memberikan informasi dan edukasi dalam bentuk seminar bagi ibu-ibu kader di Desa Rejosari Kecamatan Polokarto Kabupaten Sukoharjo. Adapun peserta seminar ini adalah ibu-ibu kader kesehatan di Desa Rejosari, Kecamatan Polokarto Kabupaten Sukoharjo sejumlah 28 orang dengan kriteria:

a. Bertempat tinggal di Desa Rejosari, Kecamatan Polokarto, Kabupaten Sukoharjo 
b. Bersedia ikut dalam kegiatan

c. Menjadi kader kesehatan dan aktif

Kegiatan pengabdian masyarakat dilaksanakan dalam 4 tahap yang meliputi:

a. Perizinan

Perijinan yang pertama dilakukan dengan menghubungi bidan desa wilayah Desa Rejosari serta pemerintah Desa Rejosari.

b. Persiapan kegiatan

1) Persiapan pengabdian masyarakat ini diawali dengan melakukan koordinasi dengan Bidan Desa wilayah Rejosari, kemudian dilanjutkan dengan koordinasi dengan ketua kader Desa Rejosari.

2) Melakukan penilaian awal kepada kader kesehatan Desa Rejosari tentang kegiatan GERMAS dan stunting

3) Menyusun booklet dan sarana lainnya yang akan digunakan pada saat kegiatan

4) Melakukan koordinasi dengan ketua kader kesehatan mengenai tempat dan waktu pelaksanaan

c. Pelaksanaan

Pelaksanaan kegiatan penyuluhan dalam bentuk seminar dilaksanakan pada tanggal 28 November 2019 dengan pemateri / narasumber dari tim pengabdian masyarakat. Pada acara berlangsung diberikan booklet tentang GERMAS dalam upaya menurunkan kejadian stunting yang dapat menjadi pegangan kader kesehatan untuk memberikan penyuluhan kepada masyarakat.

Adapun pemateri dalam kegiatan pengabdian masyarakat ini adalah:

1) Gipfel Remedina, SST.M.Keb. dengan materi pengertian dan pencegahan stunting

2) Fitria Hayu Palupi, SST., M.Kes. dengan materi GERMAS dalam pencegahan stunting

3) Siskana Dewi Rosita, SST., M.Kes. dengan materi Sanitasi Total Berbasis Masyarakat (STBM) 5 pilar untuk mencegah stunting

d. Evaluasi dengan melakukan pretest dan posttest

Output yang akan dinilai adalah kader kesehatan dapat memotivasi masyarakat secara umum untuk menerapkan GERMAS untuk sehat serta memiliki kepedulian terhadap kesehatan terutama dalam pencegahan stunting.

\section{Hasil dan Pembahasan}

Pengabdian masyarakat ini dilakukan pada hari Kamis, pada tanggal 28 November 2019, bertempat di Balai Desa Rejosari, Kecamatan Polokarto, Kabupaten Sukoharjo. Dengan jumlah peserta yang mengikuti penyuluhan ini adalah 38 peserta, terdiri dari Ketua TIM Penggerak PKK, kader kesehatan se Desa Rejosari dan perwakilan dari RT dan RW. Jumlah kader yang hadir sebanyak 26 orang kader, Sedangkan yang mewakili RT dan RW adalah pengurus RT dan RW sejumlah 11 orang yang bertugas untuk menyampaikan hasil kegiatan kepada warga.

Dalam pengabdian masyarakat ini diberikan 3 materi dengan pembicara yang berbeda. Kegiatan dimulai pukul 08.30 - 12.00 WIB, dimulai dari registrasi peserta, pembukaan, pemberian booklet untuk peserta dilanjutkan oleh materi inti. Sebelum dan setelah dilakukan penyegaran materi untuk kader, peserta diberikan pretest dan posttest (Tabel 1).

Tabel 1. Hasil pretest dan posttest

\begin{tabular}{llll}
\hline No & \multicolumn{1}{c}{ Materi } & \multicolumn{1}{c}{ Pretest } & \multicolumn{1}{c}{ Posttest } \\
\hline 1. & Pengertian stunting & Sangat baik & Sangat baik \\
2. & Penyebab stunting & Baik & Sangat baik \\
3. & Pengertian GERMAS & Sangat Baik & Sangat baik \\
4. & Komponen utama penanggulangan stunting & Baik & Sangat baik \\
5. & Pengertian STBM & Baik & Sangat baik \\
6. & Pelaksanaan STBM & Cukup & Baik \\
\hline
\end{tabular}


Pembicara Pertama, Ibu Gipfel Remedina, SST, M. Keb, memaparkan materi tentang stunting (Gambar 1). Adapun materi yang dijelaskan meliputi pengertian stunting, prevalensi stunting di Indonesia, ciri-ciri stunting yang meliputi wajah tampak lebih muda dari usianya, pertumbuhan gigi terlambat, pertumbuhan melambat, performa buruk pada tes perhatian dan memori belajar, tanda pubertas terlambat, pada usia 8-10 tahun anak menjadi lebih pendiam dan tidak melakukan eye contact. Menjelaskan tentang penyebab stunting yaitu faktor gizi buruk yang dialami oleh ibu hamil maupun anak balita, kurangnya pengetahuan ibu mengenai kesehatan dan gizi sebelum dan pada masa kehamilan maupun setelah melahirkan, masih terbatasnya layanan kesehatan, masih kurangnya akses makanan bergizi dan kurangnya akses air bersih dan sanitasi. Menjelaskan tentang dampak stunting yaitu mudah sakit, kemampuan kognitif yang berkurang, saat tua akan beresiko terkena penyakit yang berhubungan dengan pola makan, fungsi tubuh yang tidak seimbang, postur tubuh yang tidak seimbang saat dewasa. Sedangkan dampak jangka pendek stunting yaitu terganggunya perkembangan otak, pertumbuhan fisik serta gangguan metobolisme pada tubuh. Adapun cara pencegahan stunting dimulai sejak kehamilan yaitu ibu hamil mendapatkan tablet tambah darah selama kehamilannya, memberikan makanan tambahan bagi ibu hamil yang sehat dan bergizi seimbang, setelah bayi lahir lakukan Inisiasi Menyusu Dini dan bayi diberikan ASI eksklusif selama 6 bulan, setelah 6 bulan bayi tetap diberikan ASI dengan tambahan MPASI dan dilakukan pemantauan pertumbuhan bayi/ balita pada Posyandu terdekat.

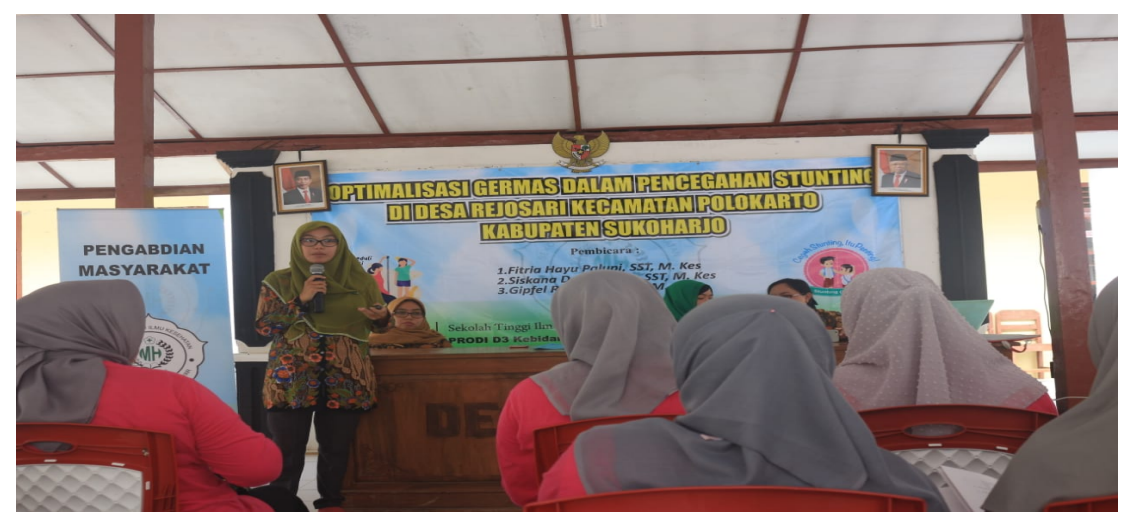

Gambar 1 . Pemaparan pembicara 1 dengan materi stunting

Pemateri kedua, ibu Fitria Hayu Palupi, SST, M. Kes, menyampaikan materi tentang GERMAS sehingga dengan menerapkan GERMAS dalam kehidupan sehari-hari dapat mencegah kejadian stunting (Gambar 2). Fokus kegiatan GERMAS yang telah dicanangkan oleh Gubernur Jawa Tengah meliputi aktivitas fisik, mengkonsumsi buah dan sayur setiap hari, cek kesehatan secara berkala, bayi diberikan ASI eksklusif selama 6 bulan, hindari merokok baik merokok aktif maupun pasif, dan fokus untuk pencegahan dan penanggunalangan stunting. Aktivitas fisik dapat dilakukan dimana saja dan kapan saja selama minimal 30 menit setiap hari. Penanggulangan stunting melalui GERMAS meliputi 3 komponen utama penanggulangan stunting yakni pola asuh, pola makan, air bersih sanitasi, serta pemanfaatan dana desa untuk menanggulangi terjadinya stunting pada wilayah desa.

Pola asuh yang diberikan untuk mencegah stunting meliputi pemberian ASI eksklusif dan pemberian imunisasi pada bayi dan balita. Sedangkan pola makan yang dianjurkan adalah sesuai dengan porsi masing masing dengan komposisi yang disesuaikan untuk pertumbuhan dan perkembangan bayi/balita. Sedangkan sanitasi yang dibutuhkan untuk mencegah terjadinya stunting yaitu dengan mengacu pada rumah sehat, bukan rumah yang bagus dan enak dipandang namun terlebih adalah rumah yang sehat, sehat bangunannya dan sehat perilaku penghuninya, GERMAS untuk mencegah stunting dalam masa kehamilan sampai anak berusia 2 tahun meliputi: mendukung ibu hamil untuk mengkonsumsi makanan yang sehat dan seimbang dalam jumlah yang cukup, membantu ibu hamil untuk memeriksakan kehamilan pada fasilitas pelayanan kesehatan, mengingatkan ibu hamil untuk minum tablet tambah darah secara teratur setiap hari, 
membantu ibu hamil untuk dapat melahirkan di fasilitas kesehatan oleh tenaga kesehatan, mendukung pelaksanaan Inisiasi Menyusu Dini dan pemberian ASI eksklusif 6 bulan, berperan aktif dalam pelayanan Posyandu dan mengajak ibu hamil dan anak bayi/balita agar datang, membantu tenaga kesehatan dalam mendampingi ibu hamil atau penanganan balita gizi kurang serta ikut mempromosikan dan melaksanakan hidup bersih dan sehat di lingkungan sekitar. Sebagai kader kesehatan tentunya dapat berperan aktif dalam melakukan deteksi dini kejadian gizi balita di Posyandu dengan cara melakukan pendaftaran bagi ibu hamil dan balita, melakukan penimbangan berat badan dan dicatat dalam KMS/ buku KIA, melakukan edukasi dan konseling pada ibu hamil dan ibu yang memiliki bayi/balita tentang hasil penimbangan serta melakukan konseling tentang makanan sehat dan gizi.

Adapun konvergensi dalam pencegahan stunting di desa dapat dilakukan dengan cara:

a. Posyandu meliputi kegiatan pencatatan calon sasaran, membentuk tim Pola Pemberian Makan Balita dan Anak (PMBA)

b. Poskesdes meliputi kegiatan rekap data sasaran, konfirmasi sasaran dan pembinaan

c. Puskesmas meliputi kegiatan konfirmasi status gizi, pemantauan jumlah dan alokasi sasaran, melakukan sosialisasi, melakukan lokakarya mini, perencanaan menu.

Selain itu untuk menanggulangi stunting pada desa, dapat memanfaatkan dana desa sesuai dengan Permendes PDTT No 16 Tahun 2018 yaitu dengan menyediakan air bersih dan sanitasi, pemberian makanan tambahan dan bergizi bagi balita, pelatihan tentang pemantauan perkembangan kesehatan ibu hamil dan menyusui, memberikan bantuan untuk Posyandu guna mendukung kegiatan pemeriksaan berkala pada ibu hamil atau ibu menyusui, pengembangan apotik hidup desa dan produk holtikultura untuk memenuhi kebutuhan gizi ibu hamil atau ibu menyusui, pengembangan ketahanan pangan di desa dan kegiatan penanganan kualitas hidup lainnya yang sesuai dengan kewenangan desa dan diputuskan dalam musyawarah desa.

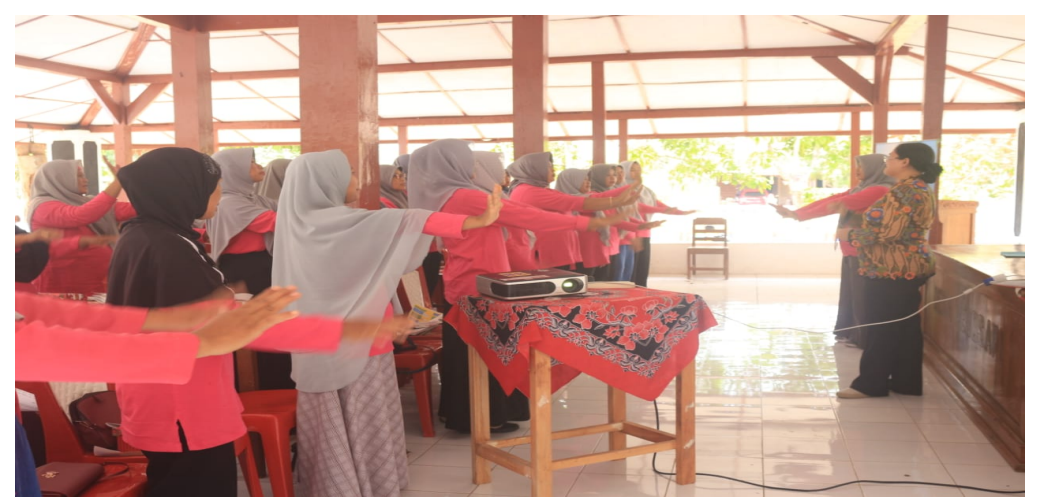

Gambar 2. Pemaparan pembicara ke-2 dengan materi GERMAS

Pembicara ketiga adalah Ibu Siskana Dewi Rosita, SST, M. Kes. yang memaparkan tentang pengembangan Sanitasi Total Berbasis Masyarakat (STBM) (Gambar 3). Penyebab tidak langsung kejadian stunting salah satunya adalah kesehatan lingkungan, sehingga dengan adanya program sanitasi yang berbasis pada kebijakan STBM kementrian kesehatan yaitu menerapkan pemberdayaan masyarakat dengan metode pemicuan untuk memperkuat budaya Perilaku Hidup Bersih dan Sehat (PHBS) pada masyarakat serta mencegah penyakit berbasis lingkungan. Adapun 5 pilar STBM yaitu Stop Buang Air Besar Sembarangan (STOP BABS), Cuci Tangan Pakai Sabun (CTPS), Pengelolaan air Minum dan Makanan Rumah Tangga (PAM RT), Pengelolaan sampah rumah tangga, Pengelolaan limbar cairan rumah tangga. Indikator keberhasilan STOP BABS yaitu apabila tidak ada masyarakat yang buang air besar di tempat yang terbuka/sembarangan misalnya di kebun, semak-semak, sungai dan lain-lain. Sedangkan pada pilar 2 yaitu CTPS masyarakat menyediakan sarana tempat cuci tangan disetiap rumah dan melakukan CTPS yang benar sebelum dan setelah makan atau melaksanakan kegiatan. Pilar 3 pengelolaan air minum dan makanan rumah tangga meliputi penyediaan sarana airu minum yang layak, bersih dan sehat misalnya air sebelum dikonsumsi direbus terlebih dahulu serta disiapkan 
wadah penyimpanan yang menjamin kualitas air minum agar terhindar dari kontaminasi ulang. Selain itu keluarga juga penyediaan makanan yang bergizi. Pilar 4 pengelolaan sampah rumah tangga dapat diolah sehingga memiliki potensi untuk diolah, misalnya pemisahan sampah organik dan anorganik serta pemanfaatannya. Sampah organik dapat diolah menjadi pupuk karena memiliki tipe mudah membusuk. Sedangkan sampah anorganik dapat dijadikan sampah komersiil yaang laku dijual dan dijadikan produk lainnya. Pilar 5 pengolahan limbah rumah tangga dikelola agar tidak mencemari sumber air minum dan tidak menjadi media berkembangbiaknya binatang pembawa penyakit. Sanitasi yang layak merupakan kunci untuk mencegah penyakit berbasis lingkungan yang menjadi penyebab terjadinya diare, cacingan, infeksi saluran pernafasan dan stunting.

Diskusi, tanya jawab, dan evaluasi dilakukan untuk mengetahui sejauh mana peserta dapat memahami penyampaian materi. Evaluasi dengan melakukan posttest bagi peserta. Sedangkan hasil yang didapatkan yaitu kader dapat menyebutkan cara pencegahan stunting, beberapa kegiatan gerakan masyarakat yaitu aktifitas fisik, mengkonsumsi buah dan sayur, cek kesehatan berkala, diberikan ASI eksklusif, enyahkan rokok dan fokus pada penanganan stunting, 5 pilar STBM. Kegiatan berjalan dengan lancar dengan suasana kondusif, kader sepakat untuk mengotimalkan GERMAS dalam upaya pencegahan stunting dengan tetap melaksanakan STBM 5 pilar dan diakhiri dengan foto bersama (Gambar 4).

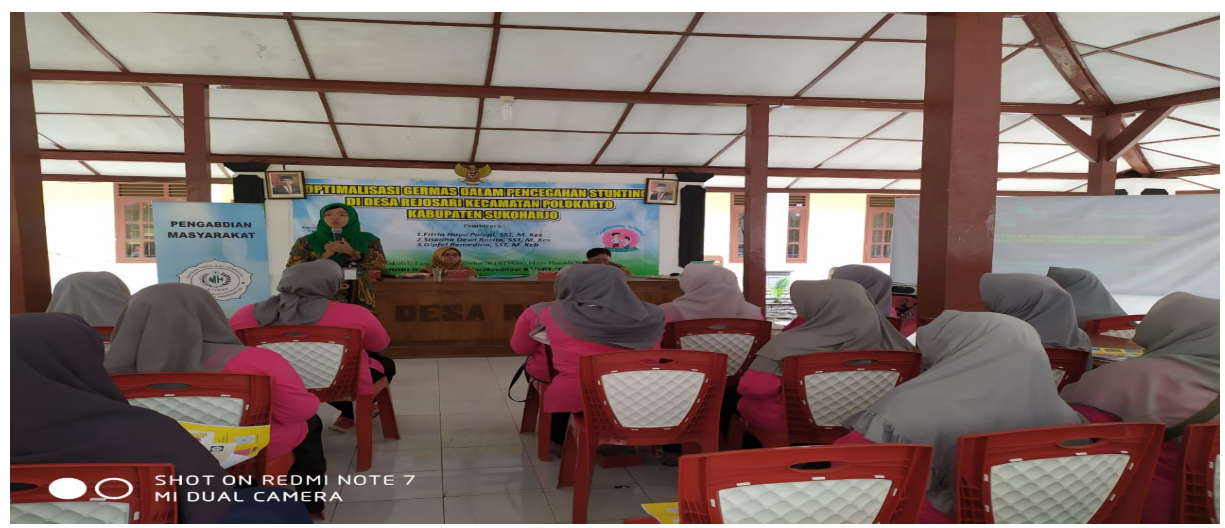

Gambar 3. Pemaparan pembicara ke-3 dengan materi STBM

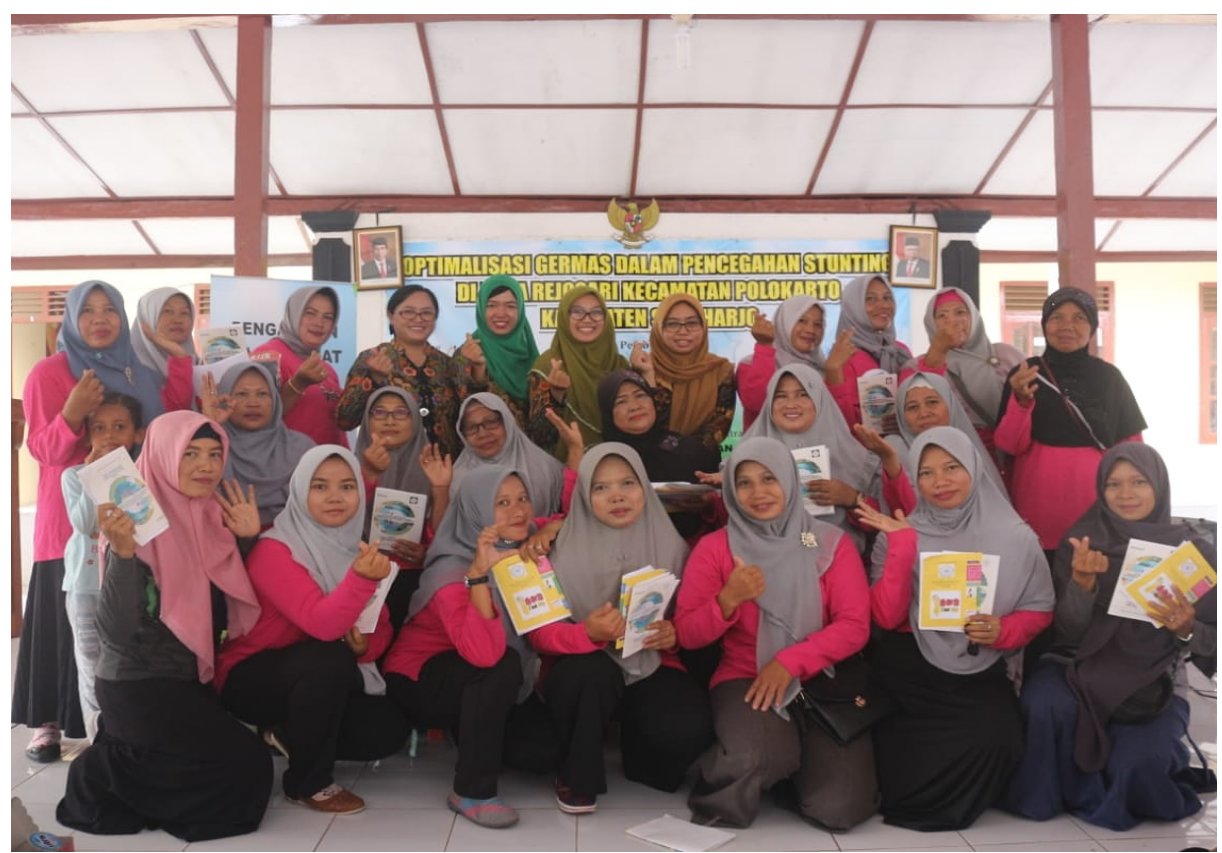

Gambar 4. Pembagian booklet 
Gerakan masyarakat hidup sehat merupakan tindakan sistematis dan terencana yang dilaksanakan secara bersama-sama oleh masyarakat. Dengan GERMAS, masyarakat diajak untuk bersama-sama membudayakan hidup sehat serta mampu mengubah kebiasaan atau perilaku tidak sehat. Dengan demikian, perlu adanya upaya yang sistematis serta didukung dengan kebijakan dan strategi untuk melaksanakan agar implementor dapat mengetahui apa yang harus dilakukan (Pangalila, Kaawoan, \& Kumayas, 2019).

Salah satu upaya untuk dapat meningkatkan pengetahuan masyarakat adalah dengan menggunakan pendidikan kesehatan. Kader dapat memberikan pendidikan kesehatan kepada masyarakat untuk melakukan pola hidup bersih dan sehat untuk menangani dan mencegah kejadian stunting (Palupi, 2011). Maywita (2018) berpendapat bahwa salah satu faktor resiko kejadian stunting karena faktor pola asuh, dengan memberikan pola asuh yang baik akan dapat mendeteksi lebih awal kejadian stunting. Penelitian yang dilakukan oleh Palupi (2017) stunting pada perempuan dapat menghambat proses pertumbuhan dan perkembangan organ reproduksi wanita. Sedangkan de Onis \& Branca (2016) berpendapat bahwa stunting pada anak merupakan malnutrisi yang dapat dimuali dari dalam rahim dan berlanjut selama 2 tahun pertama kehidupan pasca kelahiran. Adanya kerusakan fisik dan neurologi pada balita stunting dapat menyebabkan balita memiliki otak yang kerdil sehingga berpengaruh pada kognitif bayi/ balita. Solusi untuk penanganan stunting membutuhkan pendekatan multisektoral dan transdisipliner.

\section{Simpulan}

Kegiatan pengabdian masyarakat dengan memberikan refreshing peningkatan pengetahuan kader tentang stunting dan kegiatan GERMAS, penerapan STBM dalam kehidupan sehari-hari. Kader kesehatan dapat melakukan perannya melakukan deteksi dini kejadian stunting dan dapat menggerakkan masyarakat untuk melakukan hidup sehat sesuai dengan anjuran pemerintah dalam gerakan masyarakat. Mengingat bahwa kader kesehatan adalah garda depan pelayanan dan penggerak warga masyarakat terkait kesehatan.

\section{Persantunan}

Terimakasih kepada STIKes Mitra Husada Karanganyar, Kepala Desa Rejosari, Bidan Desa Rejosari, dan Puskesmas Polokarto atas ijin dan dukungan sehingga kegiatan pengabdian masyarakat dapat terlaksana dengan baik dan sukses serta dapat bermanfaat bagi kader dan warga Desa Rejosari.

\section{Referensi}

de Onis, M., \& Branca, F. (2016). Childhood stunting: a global perspective. Maternal \& Child Nutrition, 12(S1), 12-26. https://doi.org/https://doi.org/10.1111/mcn.12231

Kementerian Kesehatan Republik Indonesia. (2018). Kurikulum dan Modul Pelatihan Fasilitator STBM Sanitasi Total Berbasis Masyarakat di Indonesia. PT Aceh Media Grafika. Retrieved from http://siakpel.bppsdmk.kemkes.go.id:8102/akreditasi_kurikulum/kurikulum_20031301520 16253e3707904844c17ef8182243256c0.pdf

Maywita, E. (2018). Faktor Risiko Penyebab Terjadinya Stunting Pada Balita Umur 12-59 Bulan Di Kelurahan Kampung Baru Kec. Lubuk Begalung Tahun 2015. Jurnal Riset Hesti Medan Akper Kesdam I/BB Medan, 3(1), 56. https://doi.org/10.34008/jurhesti.v3i1.24

Palupi, F. (2011). Pengaruh pendidikan kesehatan terhadap perilaku hidup bersih dan sehat di wilayah kerja Puskesmas Jumantono Dusun Salam Desa Ngunut Kecamatan Jumantono Kabupaten Karanganyar. Jurnal Maternal, 4(04). Retrieved from https://www.ejurnal.stikesmhk.ac.id/index.php/maternal/article/download/141/126

Palupi, F., \& Anggraini, Y. (2017). Prevalensi kejadian stunting: studi cross sectional pada anak usia bawah lima tahun di Posyandu Beningrejo, Tasikmadu, Karanganyar. Maternal, II(2).

Pangalila, Y., Kaawoan, J., \& Kumayas, N. (2019). Implementasi Kebijakan Program Gerakan Masyarakat Hidup Sehat di Kota Tomohon. Implementasi Kebijakan Program Gerakan 
Masyarakat Hidup Sehat Di Kota Tomohon, 3(3), 1-9. Retrieved from

https://ejournal.unsrat.ac.id/index.php/jurnaleksekutif/article/view/23872/23525

\section{(c) (1) () $\Theta$}

(C) 2021 by the authors. Submitted for possible open access publication under the terms and conditions of the Creative Commons Attribution (CC-BY-NC-ND) license (http://creativecommons.org/licenses/by/4.0/). 